Article

\title{
Vasorelaxant Effect of Prunus mume (Siebold) Siebold \& Zucc. Branch through the Endothelium-Dependent Pathway
}

\author{
Cheolmin Jo ${ }^{1}\left(\mathbb{D}\right.$, Bumjung Kim $^{2}{ }^{(D)}$, Somin Lee ${ }^{3}$, Inhye Ham ${ }^{2}$, Kyungjin Lee ${ }^{2}(\mathbb{C}$ \\ and Ho-Young Choi ${ }^{2, *}$ \\ 1 Department of Herbal Pharmacology, Graduate School, Kyung Hee University, Seoul 02447, Korea; \\ chocm456@naver.com \\ 2 Department of Herbal Pharmacology, College of Korean Medicine, Kyung Hee University, \\ Seoul 02447, Korea; ori-pharm@hanmail.net (B.K.); iham@khu.ac.kr (I.H.); niceday@khu.ac.kr (K.L.) \\ 3 Department of Biomedical Science and Technology, Graduate School, Kyung Hee University, \\ Seoul 02447, Korea; sominleee@naver.com \\ * Correspondence: hychoi@khu.ac.kr; Tel.: +82-2-961-0325
}

Received: 19 August 2019; Accepted: 12 September 2019; Published: 13 September 2019

\begin{abstract}
Korean plum (Prunus mume (Siebold) Siebold \& Zucc.) has long been used as a health food or herbal medicine in Asia. Previous studies have shown that several plants of the genus Prunus have vasodilatory and antihypertensive effects; we hypothesized that $P$. mume branches may have a vasorelaxant effect. In this study, we evaluated the effects and action mechanism of $70 \%$ ethanol extract of P. mume branch (PMB) on isolated rat aortic rings. Inhibitors such as NG-nitro-L-arginine methyl ester, $1 H$-[1,2,4]oxadiazolo[4,3-a]quinoxalin-1-one, methylene blue, indomethacin, atropine, tetraethylammonium chloride, glibenclamide, 4 -aminopyridine and $\mathrm{BaCl}_{2}$ were used to investigate the mechanism of vasodilation responsible for the vascular relaxation. PMB $(2-30 \mu \mathrm{g} / \mathrm{mL})$ induced vasorelaxation in the presence of vascular endothelium, and all inhibitors used in this study affected the degree of relaxation. These results suggest that the vasorelaxant effect of PMB is endothelium-dependent and affects the nitric oxide-cyclic guanosine monophosphate pathway, prostacyclin pathway, muscarinic receptor pathway, and potassium channels. Our study explains that PMB may be another approach to hypertension treatment to reduce the burden of cardiovascular disease.
\end{abstract}

Keywords: Prunus mume (Siebold) Siebold \& Zucc.; vasorelaxation; endothelium-dependent; hypertension; cardiovascular disease; Korean plum

\section{Introduction}

Cardiovascular disease is the leading cause of death worldwide compared to other diseases [1], with hypertension (high blood pressure) being a major contributor to this mortality [2]. To reduce this effect, many researchers have been working extensively on drug discovery to improve hypertension treatment, such as angiotensin-converting enzyme inhibitors, angiotensin receptor blockers, calcium channel blockers, renin inhibitors, sympathoplegic agents, thiazide diuretics, $\alpha$-adrenergic blockers, $\beta$-adrenergic blockers, and vasodilators [3]. Despite the research and development of various treatment strategies, the number of adults with high blood pressure worldwide increased from 594 million in 1975 to 1.13 billion in 2015 [4]. Consequently, there is a growing need for more efficient and stable approaches for the prevention and treatment of hypertension. Among other causes, abnormalities in the regulation of vascular smooth muscle contraction cause a change in blood pressure, and an isolated increase in vascular smooth muscle is known to cause hypertension [5]. Therefore, the regulation of vascular smooth muscle using natural products may be an alternative to the treatment and prevention of hypertension. 
Korean plum, Prunus mume (Siebold) Siebold \& Zucc., is a deciduous tree of the family Rosaceae with over 3000 years of cultivation history. This species is cultivated in Korea, China, and Japan for use as landscape trees or fruit trees [6]. The fumigated fruit of $P$. mume has been used as the traditional medicine, "Omae", in Korea [7,8]. In addition, various parts of P. mume (i.e., fruit, flower, leaf, branch, seed, and root) have been used in traditional Chinese medicine. Specifically, the branch is called "Meigeng" (in Chinese) and has been used to prevent abortion [8].

In the field of basic research, the P. mume flower has been demonstrated to be involved in antioxidant activity [9] and inhibitory effects against aldose reductase and platelet aggregation [10]. P. mume fruit inhibits the proliferation of cancer cells such as Hep-2, HEC-1-B, and SK-OV-3 [11], decreases adrenocorticotropic hormone levels in menopausal rat models caused by ether stress [12], improves the fluidity of human blood ex vivo [13], and inhibits growth signals of vascular smooth muscle cells induced by angiotensin II [14]. In addition, it exhibits antimicrobial [15] and hepatoprotective [16] activities. To date, there have been many studies on P. mume fruit and flowers, but little is known about the pharmacological effects of $P$. mume branch.

Previous studies have shown that $P$. mume fruit has no significant effect on blood pressure control in hypertensive patients [17], but various parts of the plants of genus Prunus such as P. yedoensis bark [18], P. yedoensis leaf [19], P. seroina leaf [20], P. seroina fruit [21], aerial parts of $P$. lycioides [22], and prunetin (a compound isolated from $P$. yedoensis) [23] have shown vasorelaxant and anti-hypertensive effects. Furthermore, studies on chemical compounds obtained from the branch of P. mume have led to the identification of flavonoids, triterpenoids, phenolic acids, and lactones [24]. Among these compounds, 3-O-caffeoylquinic acid (chlorogenic acid), caffeic acid, rutin, and luteolin are known to have vasorelaxant effects [25-28]. Thus, we hypothesized that $P$. mume branch might have vasorelaxant effects. In order to further validate the benefits of using $P$. mume branch in the fields of pharmaceutical and functional foods, this study investigated the vasorelaxant activities of the $70 \%$ ethanol extract of $P$. mume branch (PMB) and identified the mechanisms of the vasorelaxant activities.

\section{Results}

\subsection{Vasorelaxant Effects of PMB in Rat Aortic Rings with Intact or Denuded Endothelium}

PMB caused endothelium-dependent relaxation in endothelium-intact aortic rings pre-contracted by phenylephrine $(\mathrm{PE}, 1 \mu \mathrm{M}$ ) treatment. The maximal relaxation effect was $90.00 \pm 0.73 \%$ (half maximal effective concentration $\left.\left(\mathrm{EC}_{50}\right)=8.08 \pm 1.03\right)$ and $7.83 \pm 1.00 \%\left(\mathrm{EC}_{50}=11.74 \pm 1.11\right)$ for endothelium-intact and endothelium-denuded aortic rings, respectively (Figure 1).
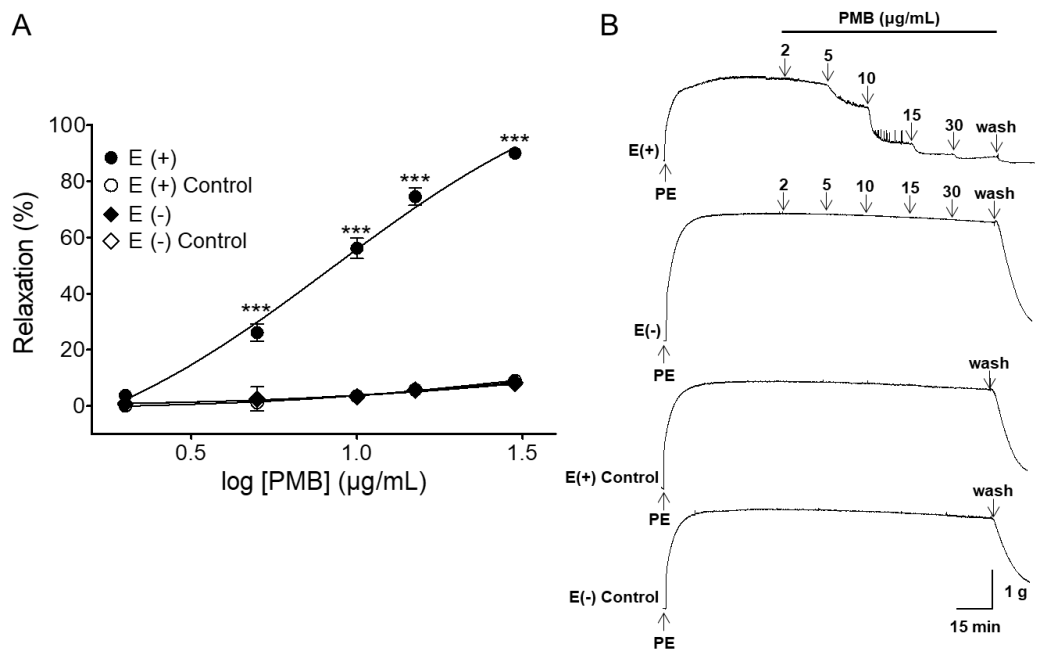

Figure 1. Cumulative concentration-response curves of PMB $(2-30 \mu \mathrm{g} / \mathrm{mL})$ in rat aortic rings with intact $[(\mathrm{E}+)]$ or denuded $[(\mathrm{E}-)]$ endothelium pre-contracted with phenylephrine $(\mathrm{PE}, 1 \mu \mathrm{M})(\mathrm{A})$. Representative traces under the indicated conditions $(\mathbf{B})$. Values are expressed as mean $\pm \operatorname{SEM}(n=6) .{ }^{* * *} p<0.001$ vs. control. 
2.2. Vasorelaxant Effect of PMB on Endothelium-Intact Aortic Rings Pre-Incubated with NG-Nitro-L-Arginine Methyl Ester (L-NAME), Indomethacin, or Combination of L-NAME and Indomethacin

The PMB-induced vasorelaxant effect was significantly decreased by L-NAME (100 $\mu \mathrm{M})$, an inhibitor of endothelial NO synthase (NOS). In the presence and absence of L-NAME, the maximal vasorelaxant effects were $20.66 \pm 1.20 \%\left(\mathrm{EC}_{50}=7.31 \pm 1.11\right)$ and $90.00 \pm 0.73 \%$, respectively. Pre-incubation with indomethacin, a cyclooxygenase inhibitor, significantly attenuated PMB-induced relaxation of endothelium-intact aortic rings pre-contracted by PE $(1 \mu \mathrm{M})$. In the presence and absence of indomethacin $(10 \mu \mathrm{M})$, the maximal relaxation effect was $47.83 \pm 3.68 \%\left(\mathrm{EC}_{50}=14.18 \pm 1.05\right)$ and $90.00 \pm 0.73 \%$, respectively. Pre-treatment with a combination of L-NAME $(100 \mu M)$ and indomethacin $(10 \mu \mathrm{M})$ significantly inhibited the vasorelaxant effect. The maximal relaxation effect was $7.00 \pm 0.25 \%$ $\left(\mathrm{EC}_{50}=12.40 \pm 1.04\right)$ (Figure 2).
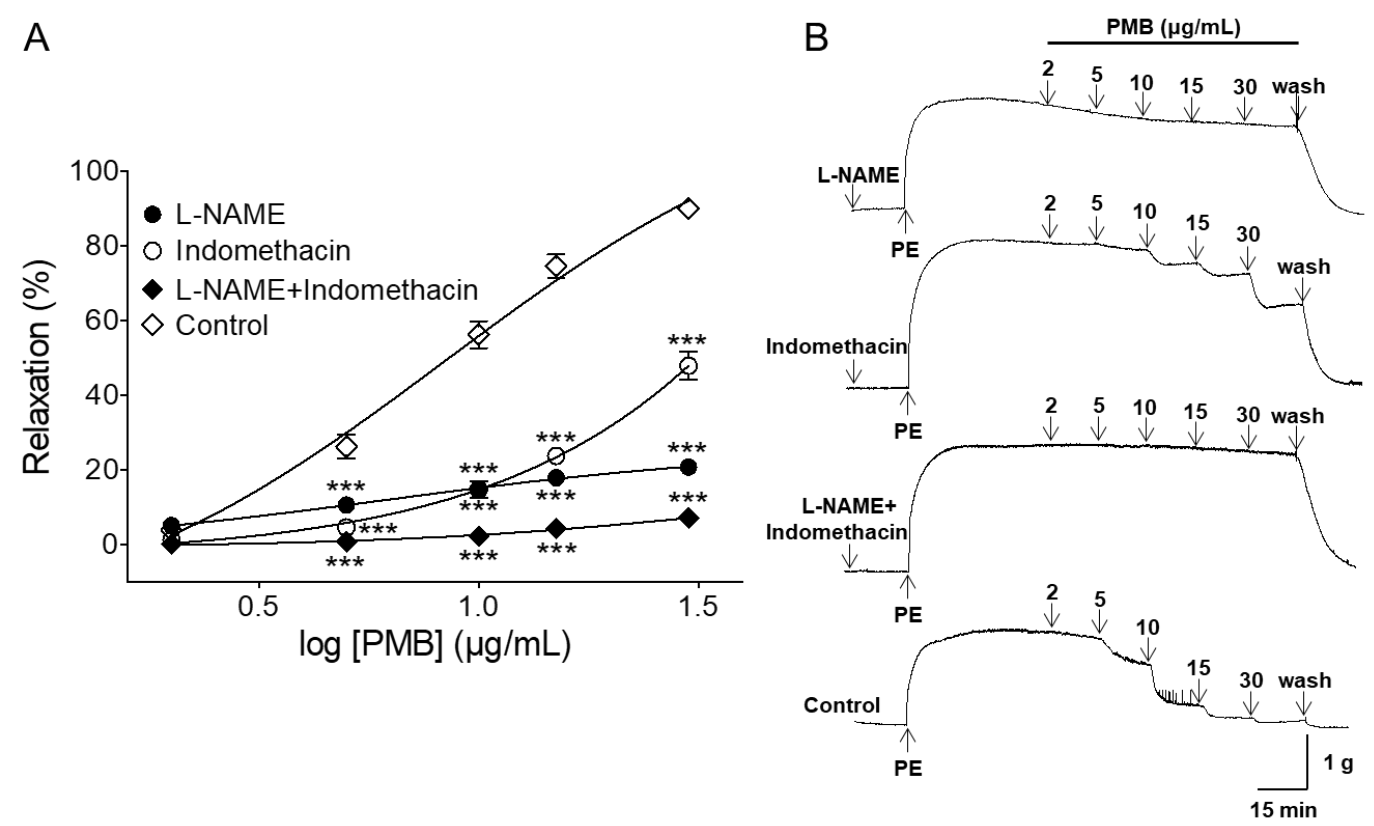

Figure 2. Concentration-dependent relaxation effect of PMB $(2-30 \mu \mathrm{g} / \mathrm{mL})$ on phenylephrine (PE, $1 \mu \mathrm{M}$ )-pre-contracted endothelium-intact aortic rings in the presence and absence (control) of NG-nitro-L-arginine methyl ester (L-NAME, $100 \mu \mathrm{M})$, or indomethacin $(10 \mu \mathrm{M})$, or a combination of L-NAME $(100 \mu \mathrm{M})$ and indomethacin $(10 \mu \mathrm{M})(\mathbf{A})$. Representative traces under the indicated conditions (B). Values are expressed as mean $\pm \operatorname{SEM}(n=6) .{ }^{* * *} p<0.001$ vs. control.

2.3. Vasorelaxant Effect of PMB on Endothelium-Intact Aortic Rings Pre-Incubated with 1H-[1,2,4]oxadiazolo[4,3-a]quinoxalin-1-One (ODQ) or Methylene Blue (MB)

The PMB-induced vascular relaxant effect was significantly inhibited by the soluble guanylate cyclase (sGC) inhibitors $1 H$-[1,2,4] oxadiazolo[4,3-a]quinoxalin-1-one (ODQ, $10 \mu \mathrm{M}$ ) or methylene blue $(\mathrm{MB}, 10 \mu \mathrm{M})$. In the presence and absence of ODQ, the maximal vasorelaxant effect was $8.16 \pm 0.40 \%$ $\left(\mathrm{EC}_{50}=6.22 \pm 1.10\right)$ and $90.0 \pm 0.7 \%$, respectively. In the presence and absence of $\mathrm{MB}$, the maximal relaxant effect was $12.50 \pm 0.84 \%\left(\mathrm{EC}_{50}=13.18 \pm 1.04\right)$ and $90.0 \pm 0.7 \%$, respectively (Figure 3). 
A

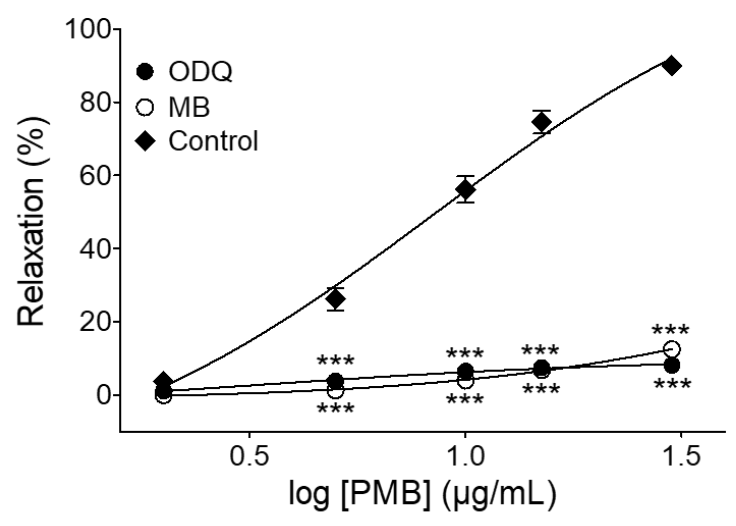

B

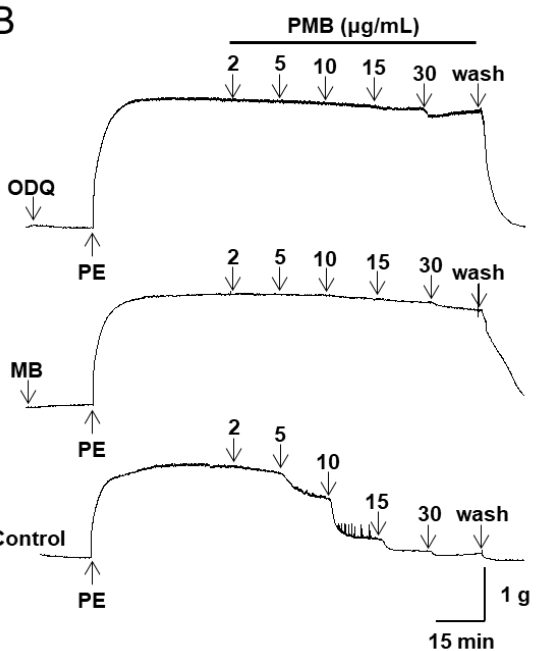

Figure 3. Concentration-dependent relaxation effect of PMB $(2-30 \mu \mathrm{g} / \mathrm{mL})$ on phenylephrine $(\mathrm{PE}, 1 \mu \mathrm{M})$-pre-contracted endothelium-intact aortic rings in the presence and absence (control) of $1 H$-[1,2,4]oxadiazolo[4,3- $\alpha$-quinoxalin-1-one $(\mathrm{ODQ}, 10 \mu \mathrm{M})$ or methylene blue $(\mathrm{MB}, 10 \mu \mathrm{M})(\mathrm{A})$. Representative traces under the indicated conditions $(\mathbf{B})$. Values are expressed as mean $\pm \operatorname{SEM}(n=6)$. *** $p<0.001$ vs. control.

\subsection{Vasorelaxant Effect of PMB on Endothelium-Intact Aortic Rings Pre-Incubated with Atropine}

Pretreatment of endothelium-intact aortic rings with atropine (muscarinic receptor antagonist) significantly diminished PMB-mediated vasorelaxation. In the presence and absence of atropine $(1 \mu \mathrm{M})$, the maximal relaxation effect was $51.00 \pm 1.50 \%\left(\mathrm{EC}_{50}=9.77 \pm 1.03\right)$ and $90.0 \pm 0.7 \%$, respectively (Figure 4).
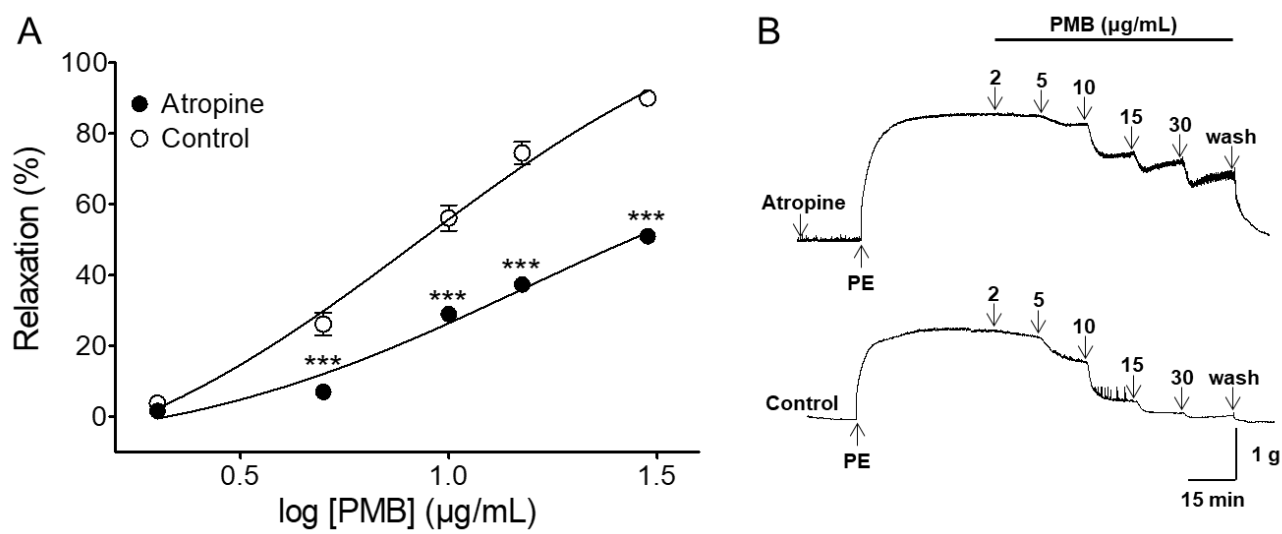

Figure 4. Relaxation responses induced by $\mathrm{PMB}(2-30 \mu \mathrm{g} / \mathrm{mL})$ on phenylephrine (PE, $1 \mu \mathrm{M})$-pre-contracted aortic rings in the presence or absence (control) of atropine $(1 \mu \mathrm{M})(\mathbf{A})$. Representative traces under the indicated conditions $(B)$. Values are expressed as mean $\pm \operatorname{SEM}(n=6)$. ${ }^{* * *} p<0.001$ vs. control.

2.5. Vasorelaxant Effect of PMB on Endothelium-Intact Aortic Rings Pre-Incubated with Various Potassium Channel Blockers

The PMB-induced vasorelaxant effect was significantly decreased by tetraethylammonium (TEA, $5 \mathrm{mM}$ ) and 4-aminopyridine (4-AP, $1 \mathrm{mM}$ ), the inhibitors of non-selective potassium channel. In the presence and absence of TEA or 4-AP, the maximal vasorelaxant effects were $25.66 \pm 1.66 \%$ $\left(\mathrm{EC}_{50}=8.39 \pm 1.07\right)$ and $62.66 \pm 1.89 \%\left(\mathrm{EC}_{50}=12.10 \pm 1.04\right)$, respectively. Pre-incubation with glibenclamide $(10 \mu \mathrm{M})$, an adenosine triphosphate (ATP)-sensitive potassium $\left(\mathrm{K}_{\mathrm{ATP}}\right)$ channel inhibitor, partially attenuated PMB-induced relaxation of endothelium-intact aortic rings pre-contracted by PE $(1 \mu \mathrm{M})$. The maximal relaxation effect was $58.66 \pm 1.97 \%\left(\mathrm{EC}_{50}=11.49 \pm 1.03\right)$. Pre-treatment with $\mathrm{BaCl}_{2}$ 
$(30 \mu \mathrm{M})$, the inward-rectifier potassium $\left(\mathrm{K}_{\mathrm{IR}}\right)$ channel blocker, significantly decreased the PMB-induced vasorelaxant effect. The maximal relaxation effect was $39.16 \pm 4.38 \%\left(\mathrm{EC}_{50}=15.19 \pm 1.06\right)$ (Figure 5).
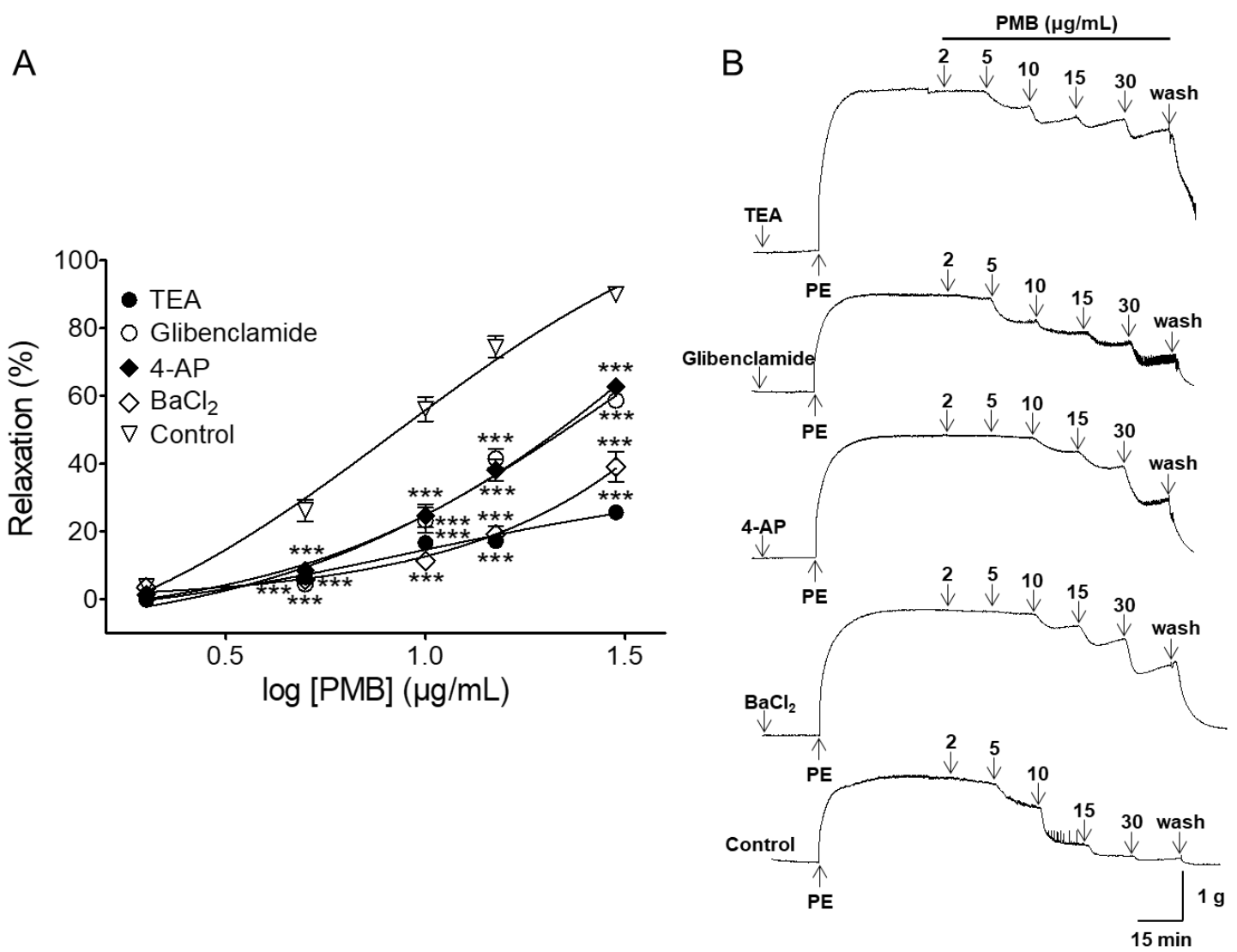

Figure 5. Relaxation responses induced by PMB $(2-30 \mu \mathrm{g} / \mathrm{mL})$ on endothelium-intact aortic rings pre-contracted with phenylephrine $(\mathrm{PE}, 1 \mu \mathrm{M})$ in the presence of tetraethylammonium (TEA, $5 \mathrm{mM}$ ), glibenclamide $(10 \mu \mathrm{M})$, 4-aminopyridine (4-AP, $1 \mathrm{mM})$, or $\mathrm{BaCl}_{2}(30 \mu \mathrm{M})(\mathbf{A})$. Representative traces under the indicated conditions $(\mathbf{B})$. Values are expressed as mean $\pm \operatorname{SEM}(n=6)$. ${ }^{* *} p<0.001$ vs. control.

\subsection{Quantitative HPLC Analysis of Compounds in PMB}

The retention time (RT) of chlorogenic acid, caffeic acid, rutin, genistein 7-O- $\beta$-glucopyranoside (G7G), prunetin 5-O- $\beta$-glucopyranoside (P5G) and luteolin were 4.61, 7.33, 8.30, 10.96, 15.66, and $23.65 \mathrm{~min}$, respectively. Standard curve was calibrated by using the linear regression derived from the peak area. The regression equation (correlation coefficient, $R^{2}$ ) of chlorogenic acid was $y=11413 x+187,910(0.9996)$, caffeic acid was $y=32,669 x+352,689(0.9986)$, rutin was $y=12,975 x+86,657(0.9999)$, G7G was $y=29625 x+118152(0.9989)$, P5G was $y=13,269 x+78,669(0.9999)$, and luteolin was $y=16,294 x+7079.5(0.9999)$, which exhibited good linearity. The standard compounds content of PMB $1 \mathrm{~g}$ was as follows: chlorogenic acid was $133.01 \pm 15.09$, caffeic acid was $10.22 \pm 10.55$, rutin was $57.02 \pm 4.50$, G7G was $61.72 \pm 3.73$, P5G was $4.27 \pm 5.58$, and luteolin was $0.43 \pm 0.09 \mu \mathrm{g}$ (Figure 6). 

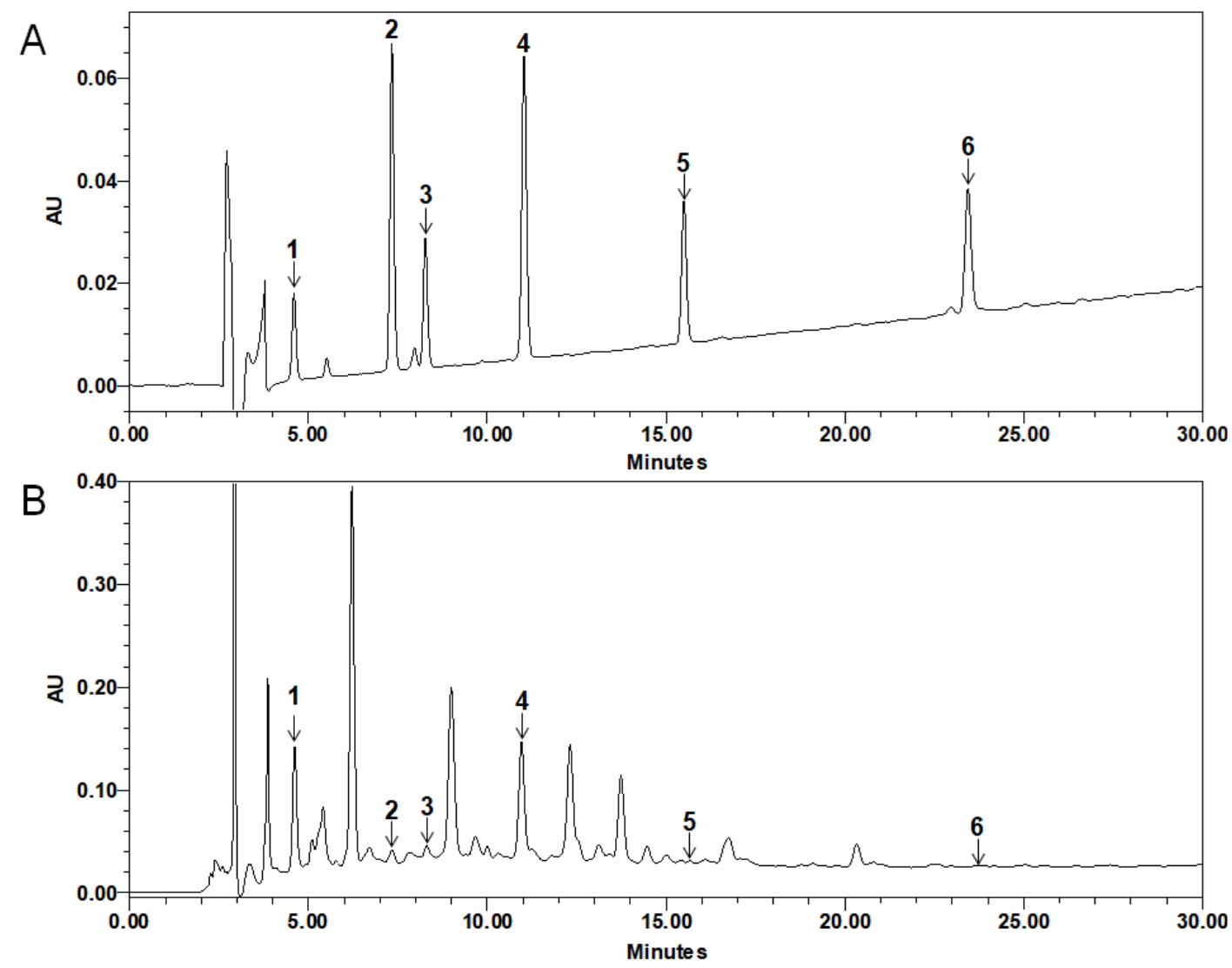

Figure 6. HPLC chromatogram of standard solution (A) and PMB (B) at $240 \mathrm{~nm}$. 1; chlorogenic acid (retention time $(\mathrm{RT})=4.61 \mathrm{~min}), 2$; caffeic acid $(\mathrm{RT}=7.33 \mathrm{~min}), 3$; rutin $(\mathrm{RT}=8.30 \mathrm{~min}), 4$; Genistein 7-O- $\beta$-glucopyranoside (G7G, RT = $10.96 \mathrm{~min}$ ), 5; prunetin 5-O- $\beta$-glucopyranoside (P5G, RT = $15.66 \mathrm{~min}$ ), 6; luteolin ( $\mathrm{RT}=23.65 \mathrm{~min})$.

\section{Discussion}

In the current study, PMB induced vasorelaxation in PE-pre-contracted endothelium-intact rat thoracic aorta. However, the effects of $\mathrm{PMB}$ on endothelium-denuded aortic rings were markedly reduced. These results suggested that the vasorelaxant effect caused by PMB was endothelium-dependent. Thus, we determined whether the mechanism of PMB vasorelaxation of the rat thoracic aorta was through an endothelium-dependent pathway and found that the vasorelaxant effect of PMB was related to NO-cGMP pathway, 4-aminopyridine prostacyclin $\left(\mathrm{PGI}_{2}\right)$, muscarinic receptor pathway, and potassium channels.

It is widely known that the vascular endothelium plays a vital role in vasorelaxation by secreting vasodilation substances such as $\mathrm{NO}, \mathrm{PGI}_{2}$, and endothelium-derived hyperpolarizing factor (EDHF). In endothelial cells, an increase in calcium concentration induces calcium binding to calmodulin. The calcium-calmodulin complex stimulates NOS to activate NO formation from L-arginine. In smooth muscle cells, NO activates soluble guanylate cyclase and increases intracellular cGMP levels. As cGMP increases, calcium levels decrease and the smooth muscle relaxes $[29,30]$. In this study, L-NAME, ODQ, or $\mathrm{MB}$ were used to investigate the endothelium-depended vasorelaxation of PMB. The vasorelaxant effect of PMB was significantly attenuated by NOS inhibitor, L-NAME, and abolished by sGC inhibitors, ODQ and MB. Thus, the results obtained suggest that PMB induces a NO-cGMP pathway.

$\mathrm{PGI}_{2}$, which is synthesized by cyclooxygenase, activates adenyl cyclase. Consequently, intracellular concentration of cyclic adenosine monophosphate increases, which leads to a reduction in the concentration of intracellular calcium in smooth muscles. As a result, the vascular smooth muscle relaxes [18,29]. In this study, indomethacin (cyclooxygenase inhibitor) significantly reduced the vasorelaxant effect of PMB. 
These findings indicate that PMB-induced vascular relaxation is mediated, in part, through NO- and COX-dependent pathways. In addition, the combination of L-NAME and indomethacin significantly inhibited the relaxation effect compared to single treatment with L-NAME or indomethacin. Thus, vascular relaxation of PMB may be exerted mainly through the NO-cGMP and $\mathrm{PGI}_{2}$ pathways.

Muscarinic receptors are present in vascular endothelial cells. Activation of muscarinic receptor on vascular endothelial cells causes increased synthesis of NO, which diffuses to adjacent vascular smooth muscle cells and causes vasodilation [31,32]. In this study, atropine, a muscarinic receptor antagonist, was shown to partially reduce the vasorelaxant effect of PMB. This result suggested that PMB regulates multiple pathways simultaneously, activating several receptors and channels, and might have a stronger tendency to activate other pathways as compared to the muscarinic receptors.

Activation of potassium channels both in the vascular smooth muscle and endothelium causes hyperpolarization which leads to vasorelaxation [33]. Apart from the endothelium-dependent and endothelium-independent vasodilatation mechanisms, potassium channels are a major mechanism involved in the regulation of vascular tone in vascular smooth muscle cells. To block potassium channels, we used the inhibitors TEA $(5 \mathrm{mM})$ and 4-AP $(1 \mathrm{mM})$, voltage-gated non-selective potassium channel blockers, glibenclamide ( $\mathrm{K}_{\mathrm{ATP}}$ channel blocker), and $\mathrm{BaCl}_{2}\left(\mathrm{~K}_{\mathrm{IR}}\right.$ channel blocker) [34,35]. Prunus mume branch-induced relaxation was partially decreased due to pretreatment with inhibitors, such as TEA, 4-AP, glibenclamide, and $\mathrm{BaCl}_{2}$. These data indicate the activation of potassium channels in the vascular smooth muscle and endothelium, including voltage-gated $\mathrm{K}_{\mathrm{ATP}}$ or $\mathrm{K}_{\mathrm{IR}}$ channels, may be involved in PMB-induced vasorelaxation.

Quantitative analysis was conducted on G7G and P5G, which are known to be present in the plant genus Prunus [36,37], and on chlorogenic acid, caffeic acid, rutin, and luteolin, which are reported to be present in Prunus mume branches [24]. The concentration of chlorogenic acid, caffeic acid, rutin, G7G, P5G, and luteolin in PMB was 133.01, 10.22, 57.02, 61.72, 4.27, and $0.43 \mu \mathrm{g}$, respectively.

In previous studies, chlorogenic acid induced direct endothelium-dependent vasodilation by increasing NOS, cyclooxygenase, and EDHF pathways on rat aortic rings. The maximum effective concentration and the maximal effect values were $10^{-4} \mathrm{M}$ and $67 \pm 4 \%$, respectively [25]. Rutin $(10-160 \mu \mathrm{M})$ caused dose-dependent vasorelaxation by NO-cGMP pathway in endothelium-intact rings pre-contracted with PE. The maximal response value was $44.28 \pm 7.48 \%$ [26]. Caffeic acid $\left(10^{-2} \mathrm{~g} / \mathrm{L}\right)$ caused relaxation activity against noradrenaline-induced contraction of rat aorta with/without endothelium [27]. Luteolin caused endothelium-dependent relaxation in endothelium-intact aortic rings pre-contracted by PE. Luteolin $(4.5-36 \mu \mathrm{mol} / \mathrm{L})$ caused a concentration-dependent relaxation in endothelium-intact or endothelium-denuded rat aortic rings precontracted with PE [28].

Quantitative analysis of PMB showed that the contents of chlorogenic acid and rutin, which cause endothelium-dependent vasorelaxation, were higher than those of other compounds. Therefore, the endothelium-dependent vasorelaxant effect of PMB may be related to compounds such as chlorogenic acid and rutin. However, since PMB possesses various known and unknown compounds, the vasorelaxant effect of PMB cannot be determined as the effect of only these two compounds. Thus, it is necessary to find more active compounds responsible for the vasorelaxant effects of PMB.

\section{Materials and Methods}

\subsection{Chemicals and Reagents}

Atropine, acetylcholine, $\mathrm{CaCl}_{2}$, caffeic acid, chlorogenic acid, ethylene glycol-bis(2-aminoethylether)$N, N, N^{\prime}, N^{\prime}$-tetraacetic acid (EGTA), formic acid, glibenclamide, glucose, G7G, indomethacin, L-NAME, luteolin, MB, ODQ, PE, P5G, rutin, TEA, 4-AP were purchased from Sigma Aldrich, Inc. (St. Louis, MO, USA). $\mathrm{KCl}, \mathrm{KH}_{2} \mathrm{PO}_{4}, \mathrm{MgSO}_{4}$ were purchased from Duksan Pure Chemicals Co., Ltd. (Ansan, Korea). $\mathrm{BaCl}_{2}, \mathrm{NaCl}, \mathrm{NaHCO}_{3}$, and urethane were purchased from Daejung Chemicals \& Metals Co., Ltd. (Siheung, Korea). Acetonitrile (HPLC grade) and Methanol (HPLC grade) were purchased from J.T. Baker 
Chemical Co., Ltd. (Phillipsburg, NJ, USA). ODQ, indomethacin, and glibenclamide were dissolved in dimethyl sulfoxide. Caffeic acid, chlorogenic acid, luteolin, P5G, G7G, and rutin were dissolved in methanol. All other drugs were dissolved in distilled water.

\subsection{Plant Material and Extraction}

Branches of P. mume were collected from Jeongmi-myeon, Dangjin-si, Chungcheongnam-do, Republic of Korea in February 2018 (Figure 7). This plant was identified by Professor Kyungjin Lee of Kyung Hee University. A voucher specimen of the P. mume branch was deposited at the College of Korean Medicine, Kyung Hee University, Seoul, Republic of Korea. P. mume branches were washed in distilled water to remove contaminants. The plant material was chopped into small pieces and dried in a convection oven. Dried P. mume branches $(280 \mathrm{~g})$ were extracted two times with $70 \%$ ethanol for $2 \mathrm{~h}$ in a reflux apparatus. The extract was filtered with filter paper before being concentrated in a rotary evaporator under reduced pressure and subsequently freeze-dried. The yield of the extract was $13 \%$ (36.5 g). The 70\% ethanol extract from the P. mume branch was completely dissolved in Krebs-Henseleit (KH) buffer.

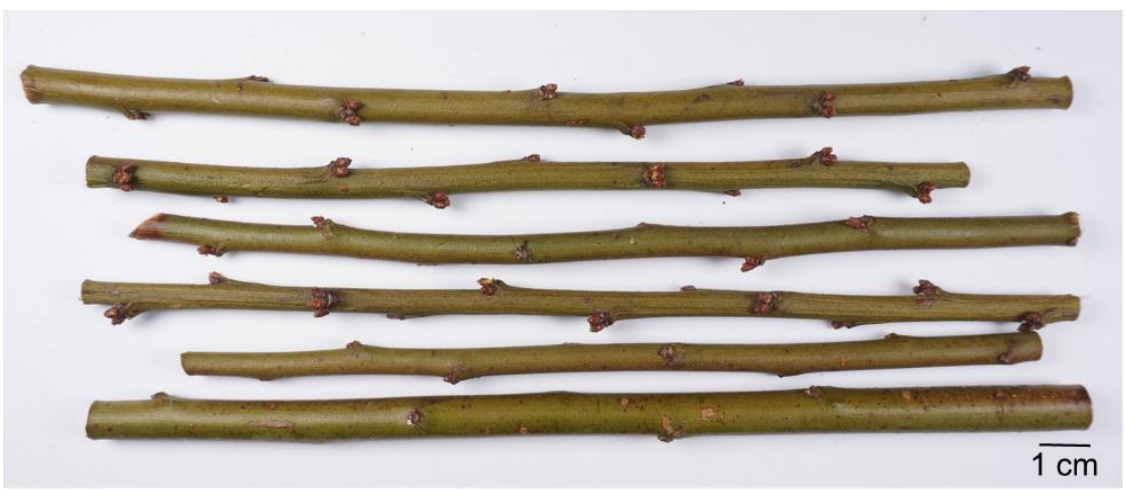

Figure 7. The branches (less than a year old) of Prunus mume (Siebold) Siebold \& Zucc.

\subsection{Animals}

Sprague-Dawley rats (SD, male, 220-260 g, 8 weeks-old) were purchased from Daehan Biolink (Chungbuk province, Korea). The animals were kept under a 12/12 h light/dark cycle and allowed free access to food and water. All procedures were executed according to the animal welfare guidelines and were approved by the Kyung Hee University Institutional Animal Care and Use Committee [KHUASP(SE)-18-074].

\subsection{Preparation of Rat Aortic Rings}

SD were anesthetized by urethane $(1.2 \mathrm{~g} / \mathrm{kg}, \mathrm{i} . \mathrm{p}$.$) , and the thoracic aorta was removed and$ immersed in $\mathrm{KH}$ (composition (mM): $\mathrm{NaCl}, 118.0 ; \mathrm{KCl}, 4.7 ; \mathrm{MgSO}_{4}, 1.2 ; \mathrm{KH}_{2} \mathrm{PO}_{4}, 1.2 ; \mathrm{CaCl}_{2}, 2.5$; $\mathrm{NaHCO}_{3}, 25.0$; and glucose, 11.1; pH 7.4), maintained at $37{ }^{\circ} \mathrm{C}$, and aerated with a mixture of $95 \%$ $\mathrm{O}_{2}$ and $5 \% \mathrm{CO}_{2}$. After connective tissue and fat were carefully removed, approximately 2-mm-long aortic rings were cut and suspended in organ baths containing $10 \mathrm{~mL} \mathrm{KH}$ at $37^{\circ} \mathrm{C}$. The rings in the organ baths were aerated with a mixture of $95 \% \mathrm{O}_{2}$ and $5 \% \mathrm{CO}_{2}$. The aortic rings were placed between 2 stainless steel wire hooks and connected to an isometric force transducer. After incubation under no tension for $20 \mathrm{~min}$, the vessel segments were allowed to equilibrate for $40 \mathrm{~min}$ at a resting tension of $1.2 \mathrm{~g}$. The KH was replaced every 20 min during the equilibration period. Changes in tension were recorded via isometric transducers connected to a data acquisition system (PowerLab, ADI instrument Co., New South Wales, Australia). The integrity of the endothelium was confirmed when acetylcholine $(10 \mu \mathrm{M})$ caused $>70 \%$ relaxation after pre-contraction by PE $(1 \mu \mathrm{M})$. 


\subsection{Experimental Protocols}

Endothelium-intact and -denuded aortic rings were pre-contracted with PE $(1 \mu \mathrm{M})$ in standard KH. After a 40 min equilibration period, cumulative concentrations of $\operatorname{PMB}(2,5,10,15$, and $30 \mu \mathrm{g} / \mathrm{mL})$ were added to the organ baths. The relaxation effect of PMB on the aortic rings was calculated as a percentage of the contraction in response to $\mathrm{PE}$.

To investigate the role of $\mathrm{NO}, \mathrm{PGI}_{2}, \mathrm{sGC}$, muscarinic receptors, or potassium channel in PMB-induced vasorelaxation, the following inhibitors were used: L-NAME (100 $\mu$ M), an NOS inhibitor; indomethacin $(10 \mu \mathrm{M})$, a cyclooxygenase inhibitor; combination of L-NAME $(100 \mu \mathrm{M})$ and indomethacin $(10 \mu \mathrm{M})$; ODQ and MB $(10 \mu \mathrm{M})$, sGC inhibitors; atropine $(1 \mu \mathrm{M})$, a muscarinic receptor antagonist; TEA (5 mM) and 4-AP (1 mM), non-selective potassium channel blockers; glibenclamide $(10 \mu \mathrm{M})$, a $\mathrm{K}_{\mathrm{ATP}}$ channel blocker; and $\mathrm{BaCl}_{2}(30 \mu \mathrm{M})$, a $\mathrm{K}_{\mathrm{IR}}$ channel blocker. The rings were pre-incubated with each blocker for 20 min before contraction by PE. Each original register was checked, and the aortic rings used did not present significant elevation of the basal tone by pre-incubation with inhibitors, such as L-NAME $(100 \mu \mathrm{M})$, indomethacin $(10 \mu \mathrm{M})$, ODQ $(10 \mu \mathrm{M})$, MB $(10 \mu \mathrm{M}), 4-\mathrm{AP}(1 \mathrm{mM})$, TEA $(5 \mathrm{mM}), \mathrm{BaCl}_{2}(30 \mu \mathrm{M})$, or glibenclamide $(10 \mu \mathrm{M})$ in vascular contractile response to PE $(1 \mu \mathrm{M})$.

\subsection{Quantitative HPLC Analysis of Compounds in PMB}

Precisely $100 \mathrm{mg}$ of PMB was weighed and dissolved in $10 \mathrm{~mL}$ of methanol. The extract was then filtered through a $0.45 \mu \mathrm{m}$ syringe filter. The standard compounds used for the quantitative analysis of PMB were chlorogenic acid, caffeic acid, rutin, G7G, P5G, and luteolin. One milligram of the standards was dissolved to give serial concentrations $(50,25$, and $12.5 \mu \mathrm{g} / \mathrm{mL}$ for each sample) and HPLC chromatograms of the standards were obtained. The relationship between the concentration and the peak-area was measured by the minimum square method ( $\mathrm{R}^{2}$ value). The HPLC apparatus was Alliance HPLC System equipped with a Waters e2695 separation module, a Waters 2998 Photodiode Array (PDA) detector (Waters Corp., Milford, MA, USA) and Empower 2 software (Waters Corp.). A YMC-Triart $4.60 \times 250 \mathrm{~mm}$ C18 reversed-phase column with $5 \mu \mathrm{m}$ particles was used. The mobile phase consisted of $0.1 \%$ formic acid (A) and acetonitrile (B) in a ratio specified by the following binary gradient with linear interpolation: $0 \mathrm{~min} 20 \% \mathrm{~B}, 30 \mathrm{~min} 40 \% \mathrm{~B}$. The column eluent was monitored at UV $240 \mathrm{~nm}$ (PDA), following which all solvents were degassed with a micromembrane filter. Chromatography was performed at room temperature at a flow rate of $1 \mathrm{~mL} / \mathrm{min}$, and $10 \mu \mathrm{L}$ was analyzed for $30 \mathrm{~min}$. The quantity of the PMB was expressed as follows: the amount (mg) of standard compound $=$ the quantitative amount $(\mathrm{mg})$ of compound $\times \mathrm{AT} / \mathrm{AS} / \mathrm{n}(\mathrm{n}=4$; AT $=$ the peak-area of the test sample containing the standard; AS = the peak-area of the standard).

\subsection{Statistical Analysis}

The values are expressed as the mean \pm standard error of mean (SEM). Statistical analysis was performed using two-way ANOVA, and Bonferroni post-hoc test was conducted using GraphPad Prism 5 software (San Diego, CA, USA). The $p<0.05$ was considered statistically significant. In all the experiments, $\mathrm{n}$ is equal to the number of aortic rings isolated from $2-3$ rats.

\section{Conclusions}

PMB caused endothelium-dependent vasorelaxation in rat aortic rings. The vasorelaxant activity of PMB were related to (1) NO-cGMP pathway, (2) $\mathrm{PGI}_{2}$ pathway, (3) muscarinic receptor pathway, and (4) potassium channels such as $\mathrm{K}_{\mathrm{V}}$ channel, $\mathrm{K}_{\mathrm{ATP}}$ channel, and $\mathrm{K}_{\mathrm{IR}}$ channel. Further studies are needed to investigate the specific vasodilative compounds of PMB and the precise mechanisms of its action.

Author Contributions: Animal experiments, C.J. and B.K.; HPLC analysis I.H. and S.L.; writing-original draft preparation, C.J.; writing-review and editing, K.L. and H.-Y.C.

Funding: This research received no external funding.

Conflicts of Interest: The authors declare no conflict of interest. 


\section{References}

1. World Health Organization. Available online: https://www.who.int/cardiovascular_diseases/about_cvd/en/ (accessed on 9 August 2019).

2. World Health Organization. Available online: https://www.who.int/nmh/publications/ncd-profiles-2018/en/ (accessed on 10 August 2019).

3. Al Disi, S.S.; Anwar, M.A.; Eid, A.H. Anti-hypertensive herbs and their mechanisms of action: Part I. Front Pharmacol 2016, 6, 323. [CrossRef] [PubMed]

4. Zhou, B.; Bentham, J.; Di Cesare, M.; Bixby, H.; Danaei, G.; Cowan, M.J.; Paciorek, C.J.; Singh, G.; Hajifathalian, K.; Bennett, J.E. Worldwide trends in blood pressure from 1975 to 2015: A pooled analysis of 1479 population-based measurement studies with 19. 1 million participants. Lancet 2017, 389, 37-55. [CrossRef]

5. Brozovich, F.V.; Nicholson, C.J.; Degen, C.V.; Gao, Y.Z.; Aggarwal, M.; Morgan, K.G. Mechanisms of Vascular Smooth Muscle Contraction and the Basis for Pharmacologic Treatment of Smooth Muscle Disorders. Pharmacol. Rev. 2016, 68, 476-532. [CrossRef] [PubMed]

6. Likuo, F.; Tao, H. Higher Plants of China; Qingdao Publishing House: Shandong, China, 2003; Volume 6, p. 761.

7. Choi, H.; Bu, Y.; Kwon, D.; Lee, J.; Oh, M.; Seo, B. Bonchohak; Younglim-sa: Seoul, Korea, 2002; pp. $958-960$.

8. Zhonghua Bencao EditCommittee. Zhonghua Bencao; Shanghai Science and Technology Press: Shanghai, China, 1999; Volume 4, pp. 86-93.

9. Shi, J.; Gong, J.; Liu, J.E.; Wu, X.; Zhang, Y. Antioxidant capacity of extract from edible flowers of Prunus mume in China and its active components. Lebensm. Wiss. Technol. 2009, 42, 477-482. [CrossRef]

10. Yoshikawa, M.; Murakami, T.; Ishiwada, T.; Morikawa, T.; Kagawa, M.; Higashi, Y.; Matsuda, H. New flavonol oligoglycosides and polyacylated sucroses with inhibitory effects on aldose reductase and platelet aggregation from the flowers of Prunus mume. J. Nat. Prod. 2002, 65, 1151-1155. [CrossRef] [PubMed]

11. Jeong, J.T.; Moon, J.-H.; Park, K.-H.; Shin, C.S. Isolation and characterization of a new compound from Prunus mume fruit that inhibits cancer cells. J. Agric. Food Chem. 2006, 54, 2123-2128. [CrossRef]

12. Ina, H.; Yamada, K.; Matsumoto, K.; Miyazaki, T. Effects of benzyl glucoside and chlorogenic acid from Prunus mume on adrenocorticotropic hormone (ACTH) and catecholamine levels in plasma of experimental menopausal model rats. Biol. Pharm. Bull. 2004, 27, 136-137. [CrossRef]

13. Chuda, Y.; Ono, H.; Ohnishi-Kameyama, M.; Matsumoto, K.; Nagata, T.; Kikuchi, Y. Mumefural, citric acid derivative improving blood fluidity from fruit-juice concentrate of Japanese apricot (Prunus mume Sieb. et Zucc). J. Agric. Food Chem. 1999, 47, 828-831. [CrossRef]

14. Utsunomiya, H.; Takekoshi, S.; Gato, N.; Utatsu, H.; Motley, E.D.; Eguchi, K.; Fitzgerald, T.G.; Mifune, M.; Frank, G.D.; Eguchi, S. Fruit-juice concentrate of Asian plum inhibits growth signals of vascular smooth muscle cells induced by angiotensin II. Life Sci. 2002, 72, 659-667. [CrossRef]

15. Pi, K.; Lee, K. Prunus mume extract exerts antioxidant activities and suppressive effect of melanogenesis under the stimulation by alpha-melanocyte stimulating hormone in B16-F10 melanoma cells. Biosci. Biotech. Biochem. 2017, 81, 1883-1890. [CrossRef]

16. Khan, A.; Pan, J.H.; Cho, S.; Lee, S.; Kim, Y.J.; Park, Y.H. Investigation of the Hepatoprotective Effect of Prunus mume Sieb. et Zucc Extract in a Mouse Model of Alcoholic Liver Injury Through High-Resolution Metabolomics. J. Med. Food 2017, 20, 734-743. [CrossRef] [PubMed]

17. Takemura, S.; Yoshimasu, K.; Fukumoto, J.; Mure, K.; Nishio, N.; Kishida, K.; Yano, F.; Mitani, T.; Takeshita, T.; Miyashita, K. Safety and adherence of Umezu polyphenols in the Japanese plum (Prunus mume) in a 12-week double-blind randomized placebo-controlled pilot trial to evaluate antihypertensive effects. Environ. Health Prev. Med. 2014, 19, 444. [CrossRef] [PubMed]

18. Lee, K.; Ham, I.; Yang, G.; Lee, M.; Bu, Y.; Kim, H.; Choi, H.-Y. Vasorelaxant effect of Prunus yedoensis bark. BMC Complement Altern. Med. 2013, 13, 31. [CrossRef] [PubMed]

19. Lee, K.; Kim, K.-W.; Heo, H.; Ham, I.; Lee, M.-H.; Kim, B.; Bu, Y.; Kim, H.; Choi, H.-Y. Vasorelaxant Effect of Prunus yedoensis leaf on Rat Aortic Rings. Kor. J. Herbol. 2013, 28, 63-69. [CrossRef]

20. Ibarra-Alvarado, C.; Rojas, A.; Luna, F.; Rojas, J.I.; Rivero-Cruz, B.; Rivero-Cruz, J.F. Vasorelaxant constituents of the leaves of Prunus serotina "capulín". Rev. Latinoam. Quim 2009, 37, 164-173.

21. Luna-Vázquez, F.; Ibarra-Alvarado, C.; Rojas-Molina, A.; Romo-Mancillas, A.; López-Vallejo, F.; Solís-Gutiérrez, M.; Rojas-Molina, J.; Rivero-Cruz, F. Role of nitric oxide and hydrogen sulfide in the vasodilator effect of ursolic acid and uvaol from black cherry Prunus serotina fruits. Molecules 2016, 21, 78. [CrossRef] 
22. Babaei, H.; Sadeghpour, O.; Nahar, L.; Delazar, A.; Nazemiyeh, H.; Mansouri, M.R.; Poursaeid, N.; Asnaashari, S.; Moghadam, S.B.; Sarker, S.D. Antioxidant and vasorelaxant activities of flavonoids from Amygdalus lycioides var. horrida. Turk. J. Biol. 2008, 32, 203-208.

23. Kim, B.; Jo, C.; Choi, H.-Y.; Lee, K. Prunetin Relaxed Isolated Rat Aortic Rings by Blocking Calcium Channels. Molecules 2018, 23, 2372. [CrossRef]

24. Lu, B.; Wu, X.; Dong, Y.; Gong, J.; Zhang, Y. Mutagenicity and safety evaluation of ethanolic extract of Prunus mume. J. Food Sci. 2009, 74, T82-T88. [CrossRef]

25. Tom, E.N.L.; Girard-Thernier, C.; Demougeot, C. The Janus face of chlorogenic acid on vascular reactivity: A study on rat isolated vessels. Phytomedicine 2016, 23, 1037-1042. [CrossRef]

26. Zhou, X.; Yao, H.; Xia, M.; Cao, C.; Jiang, H.; Xia, Q. Comparison of vasodilatation effect between quercetin and rutin in the isolated rat thoracic aorta. Zhejiang Da Xue Xue Bao. Yi Xue Ban 2006, 35, 29-33. [PubMed]

27. Andriambeloson, E.; Magnier, C.L.; Haan-Archipoff, G.; Lobstein, A.; Anton, R.; Beretz, A.; Stoclet, J.C.; Andriantsitohaina, R. Natural dietary polyphenolic compounds cause endothelium-dependent vasorelaxation in rat thoracic aorta. J. Nutr. 1998, 128, 2324-2333. [CrossRef] [PubMed]

28. Jiang, H.; Xia, Q.; Wang, X.; Song, J.; Bruce, I. Luteolin induces vasorelaxion in rat thoracic aorta via calcium and potassium channels. Pharmazie 2005, 60, 444-447. [PubMed]

29. Stankevičius, E.; Kèvelaitis, E.; Vainorius, E.; Simonsen, U. Role of nitric oxide and other endothelium-derived factors. Medicina (Kaunas) 2003, 39, 333-341. [PubMed]

30. Forstermann, U.; Munzel, T. Endothelial nitric oxide synthase in vascular disease: From marvel to menace. Circulation 2006, 113, 1708-1714. [CrossRef] [PubMed]

31. Caulfield, M.P.; Birdsall, N.J. International Union of Pharmacology. XVII. Classification of muscarinic acetylcholine receptors. Pharmacol. Rev. 1998, 50, 279-290. [PubMed]

32. Furchgott, R.F.; Zawadzki, J.V. The obligatory role of endothelial cells in the relaxation of arterial smooth muscle by acetylcholine. Nature 1980, 288, 373. [CrossRef] [PubMed]

33. Adams, D.J.; Barakeh, J.; Laskey, R.; Van Breemen, C. Ion channels and regulation of intracellular calcium in vascular endothelial cells. FASEB J. 1989, 3, 2389-2400. [CrossRef]

34. Nelson, M.T.; Quayle, J.M. Physiological roles and properties of potassium channels in arterial smooth muscle. Am. J. Physiol. Cell Physiol. 1995, 268, C799-C822. [CrossRef]

35. Tykocki, N.R.; Boerman, E.M.; Jackson, W.F. Smooth Muscle Ion Channels and Regulation of Vascular Tone in Resistance Arteries and Arterioles. Compr. Physiol. 2017, 7, 485-581.

36. Lee, J.; Yang, G.; Lee, K.; Lee, M.-H.; Eom, J.-W.; Ham, I.; Choi, H.-Y. Anti-inflammatory effect of Prunus yedoensis through inhibition of nuclear factor- $\mathrm{kB}$ in macrophages. BMC Complement Altern. Med. 2013, 13, 92. [CrossRef] [PubMed]

37. Geibel, M.; Geiger, H.; Treutter, D. Tectochrysin 5-and genistein 5-glucosides from the bark of Prunus cerasus. Phytochemistry 1990, 29, 1351-1353. [CrossRef]

Sample Availability: Samples of the compounds are not available from the authors.

(C) 2019 by the authors. Licensee MDPI, Basel, Switzerland. This article is an open access article distributed under the terms and conditions of the Creative Commons Attribution (CC BY) license (http://creativecommons.org/licenses/by/4.0/). 